\title{
Role of Demand Side Management Techniques in Reducing Electricity Demand of Residential Users
}

\author{
Ayman Uddin Mahin, Fabliha Ahmed, S. M. Ishraqul Huq, Nahid-Ur-Rahman Chowdhury
}

\begin{abstract}
Demand of electrical energy is growing day by day worldwide. To meet this increasing demand, generation is needed to be increased subsequently. Increasing generation is not an easy task as it may require setting up new generating units, changing transmission lines, control equipments, etc. Moreover, increased generation also causes increased environment pollution. An alternate approach that can create balance between demand and supply of electricity without increasing generation is demand side management (DSM). Furthermore, demand side management has the potential to reduce the use of energy resources resulting in less environment pollution. In this paper, three DSM techniques: using solar system, load limiting, deliberate load reduction are applied for residential users of Dhaka, Bangladesh and the results are compared with two traditional techniques: energy efficiency, direct load control. It has been found that by using solar system at home significant amount of electrical energy can be saved.
\end{abstract}

Index Terms- Demand side management, electrical energy, using solar system, load limiting, deliberate load reduction

\section{INTRODUCTION}

Generators or power plants are required to meet the increasing demand of electricity. This refers increasing use of energy resources which are limited and subjected to be finished one day. Due to this, it is so important to control the demand of electricity at the user end. Moreover, balancing between demand and supply is an important aspect of operating an electrical system [1]. If this balance is not maintained, undesired results like load shedding can occur. In order to maintain this balance, either generation can be increased or the demand can be controlled. The second approach is more suitable as it does not require any major modification in the power system.

Demand side management (DSM) is a set of concepts that can help to reduce electricity demand. It also reduces the necessity of setting up new power plants or generators [2]. DSM can be residential, industrial or commercial. It is used to control the loads to achieve a better overall network performance. It also allows consumers to save money and incentive is also given sometimes for reducing energy usage. In other words, DSM is the approach that helps consumers to reduce electrical energy consumption and cost [3]. Consumers play the lead role in DSM. If they are not concerned about saving electricity and aware of its importance, it is very hard to control the demand. Utilities

Ayman Uddin Mahin is with Department of Electrical and Electronic Engineering of Ahsanullah University of Science and Technology, Dhaka Bangladesh. (email: aumahin125@gmail.com).

Fabliha Ahmed is with Department of Electrical and Electronic Engineering of Ahsanullah University of Science and Technology, Dhaka, Bangladesh. (email: fabliha027@gmail.com).



Fig. 1. Zone wise supply against generation

and consumers should come forward together in this case. If each and every electricity user is concerned about DSM, a great saving in electricity is possible.

Dhaka the capital of Bangladesh has a huge population. The largest share of generated electricity in Bangladesh is supplied to Dhaka. Fig. 1 shows zone wise supply against highest generation on May 29, 2019, when 36.76\% of total generated electricity was supplied to the capital [4].

In [5], Impact of DSM techniques: energy efficiency and Direct load control is shown for reducing energy consumption of residential electricity users of Dhaka, Bangladesh. In this paper, three methods of DSM, namely, using solar system, load limiting and deliberate load reduction are applied and impact of these methods on the residential users of Dhaka is analyzed. Load limiting and deliberate load reduction are the two new DSM methods proposed in this paper. Results of the proposed methods are then compared to the methods proposed in [5].

Rest of the paper is arranged as follows: Section II discusses about some existing DSM techniques, Section III gives idea about the applied DSM methods for residential consumers of Dhaka, Section IV describes the methodology used, Section V shows the results obtained and finally section VI focuses on the summary of the paper.

S. M. Ishraqul Huq is with Department of Electrical and Electronic Engineering of Ahsanullah University of Science and Technology, Dhaka, Bangladesh. (email: ishraqulhuq@gmail.com).

Nahid-Ur-Rahman Chowdhury is with Department of Electrical and Electronic Engineering of Ahsanullah University of Science and Technology, Dhaka, Bangladesh. (email: nahid.eee.aust@gmail.com). 


\section{LITERATURE REVIEW}

\section{A. Energy Efficiency}

Energy efficiency refers to saving energy by using energy efficient technologies and equipment, reducing energy loss in the existing systems and so on [6]. Electrical energy can be saved by changing conventional lights, using automated thermostat, proper maintenance, etc. In [7], energy efficiency and DSM approaches in Abu Dhabi was discussed. The energy efficiency initiatives include developing building codes for energy efficient building design, development of energy conservation codes, sustainable school design and DSM energy management schemes in existing building.

In [8] two identical rooms: one with conventional utilities and another with highly efficient utilities were considered for demonstrating the impact of using energy efficiency. A scheduled controlling mechanism is also incorporated in the room equipped with energy efficient utilities and the results are observed. It is found that power saving of around $57 \%$ and $18 \%$ is possible for lighting load and fan, respectively by using energy efficiency approach. Moreover, energy efficient light increases the visual comfort and energy efficient fan provides better air flow and reduces noise level significantly. Furthermore, with the use of scheduled control, overall 25.5 $\%$ of room energy is saved.

To reduce energy consumption of a construction project, an audit was conducted by the authors of [9]. The energy audit is carried out on the basis of data collection, visual inspection, observations on the general condition of the facility and equipment, identification of energy consumption and other parameters. It is observed that $42 \%$ of total energy consumption can be saved by energy efficiency approach with increased cost of $2 \%$ or less.

\section{B. Direct Load Control}

Direct load control is a method of reducing demand by disconnecting some loads that have the potential to be turned OFF for a limited period of time and controlling loads. Authors of [10] proposed a DSM structure for equipment control. The structure includes a utility central server and consumer servers. Communication link is established between the utility server and the consumer servers for exchange of information. Another system for direct load control was proposed in [11] that can control load through communicating through parallel port with the help of a software. Reduction in energy consumption is observed in the load curve for using the proposed system.

Authors of [12] classified controllable appliances into three categories: static, programmable and dimmable. The programmable appliances is further divided into two sub categories, namely, static programmable and dynamic programmable. Among the three types of appliances, dimmable appliances are given priority in the case of controlling as controlling these loads have less impact on user comfort. An algorithm is also proposed for controlling different types of loads using load shedding and smart direct load control. The smart direct load control assists load shedding in maintaining demand and supply balance.
Air conditioning loads were targeted for controlling in [13]. A system is proposed that is capable of direct load control of air conditioning loads in a high density residential building. The system involves a direct load control server and building network. The building network is connected to the server and the air condition units (ACU). With the help of an algorithm controlling of ACUs is performed.

\section{Time of Use (ToU)}

Time of use refers strategies that changes electricity consumption pattern of consumers based on pricing. Authors of [14] examined impact of ToU programs on residential users of Shanghai, China. The ToU program includes usage based three step rates of electricity for peak and valley period. Rate during peak period is higher than the rate during valley period. Financial benefit of utility company and consumers is also evaluated under zero-pricing ToU, where cost of electricity is set to $\$ 0$ for valley period. By following this method, monthly electricity bill can be saved up to $80 \%$.

A demand response scheme dependent on ToU, photovoltaic generation and net-metering service is presented in [15]. The proposed scheme requires minimal sensing and net energy flow at specified intervals. A communication link is established between the smart meter and a demand response controller. The demand response controller takes necessary steps to control demand of the consumer. It is illustrated that the proposed method can effectively reduce cost within a ToU pricing structure. The scheme is also capable of shifting load from peak to off-peak and vice versa depending on energy flow.

Authors of [16] proposed a stochastic model for optimal energy management in micro-grid. In this case, improved time of use demand response schemes, grid connected and islanded mode of micro-grid are considered. By applying appropriate ToU rates for peak period, off-peak period and valley period, optimal operation of the micro-grid is possible. The scheme has also the potential to reduce production of expensive units in peak hours, total operation cost and load shedding.

\section{Solar based DSM}

Integrating renewable energy to the grid is a challenging issue. Authors of [17] analyzed different aspects of renewable energy penetration to the grid. Energy penetration to the grid from photovoltaic (PV) source is higher under net metering mechanism than feed in tariff mechanism. In feed in tariff mechanism, all generated PV power is transferred to the grid, whereas, power after meeting the home demand is injected to the grid. In net metering mechanism, PV power penetration is higher when the price of electricity is higher, DSM techniques and storage system are available.

In [18], a DSM algorithm was proposed for smart house considering historic data of consumer's habit and PV generation forecasts. The smart house contains commonly used surveillance and command of controls appliances. Appliances are scheduled in such a way to utilize the PV production as much as possible. To implement proper scheduling algorithm constraints, namely, balancing constraint, phase energy, uninterruptible phase and user time 
preferences are considered. By scheduling the appliances properly and using solar system, electricity bill can be reduced. Effectiveness of PV power penetration under load shifting scenario is also demonstrated in [19].

\section{E. Artificial Neural Network based DSM}

Artificial neural network (ANN) is the network containing artificial neurons that are modeled based on human brain. A DSM technique incorporating load shifting approach was presented in [20]. A test system containing 109 devices is taken into consideration and a neural network is used to minimize mean square error. Around $23 \%$ of cost saving is possible by shifting load and performance criterion of mean square error is minimized to $1.02 \times 10^{-9}$.

An optimization method to a demand side energy management system was proposed in [21]. In this case, a cluster of interconnected price responsive demand in an academic campus supplied by both main grid and stochastic distributed energy resources is considered. The consumers have the flexibility to use their own strategy to regulate the load and prices. An ANN is applied to predict the future power consumption of the cluster. The algorithm permits the cluster to store, sell and buy electricity at suitable time for adjusting the hourly load level. Moreover, the ANN based algorithm has the potential to increase efficiency and minimize the losses. Another method using ANN based prediction algorithm for DSM was proposed in [22] that integrates both conventional and non-conventional energy sources. In this model, the energy management unit is trained and enhanced to effectively manage the energy with hourly prediction of a power consumption limit. The algorithm is capable of reducing the power consumption by $2.05 \mathrm{KW}$ and carbon dioxide emission by $0.88 \mathrm{~kg}$ per one working day.

\section{APPLIED DSM METHODS}

\section{A. Using Home Solar System}

Solar power system is the system that converts the energy of sunlight into electricity. This renewable energy is free of cost and can be used easily to reduce the demand to the utilities. Solar system can be implemented on the roof top of a building for supplying electrical energy to home appliances. Fig. 2 gives an idea about solar power system for home. Power generated from roof top solar system can be used for home appliances with low power requirement, for instance, light and fan. Extra electricity that is produced, can be supplied directly to the grid. By doing this, consumers can also earn money.

\section{B. Load Limiting}

In this method, a limit will be set during peak ( 5 pm -11 $\mathrm{pm}$ ) which is $5-20 \%$ less than the demand of a residential user in previous day. The method is to be performed with interval of one day. An arrangement should be such that consumers should be informed when demand crosses the set value. A Smart metering system can be used which will provide an indication accordingly. Consumers will have the flexibility to select loads for reducing the demand. This method will encourage consumers to shift loads, to use energy efficient appliances and to reduce unnecessary consumption. Incentive can also be given to the consumers for following this method. They can also save money by reducing or shifting loads for limiting load during peak.

\section{Deliberate Load Reduction}

Load reduction simply means reducing electrical energy usage by turning some loads OFF. Encouragement and incentives are the keys of deliberate load reduction. Utility does not have any sort of control over electricity usage of the consumers. So, incentives can be provided for reducing electricity usage during peak or throughout the day. Small saving of electricity in each household can reduce the system peak at a noticeable amount.

\section{METHODOLOGY}

Necessary base curves are developed using the data collected from a survey on 32 residential electricity users of Dhaka. Then, demand side management tools: using solar system, load limiting and deliberate load reduction are applied and the benefits are calculated. In the case of using solar system, lighting load and fan are targeted. For load limiting method, limit for $20 \%$ load limiting is set during peak. For deliberate load reduction method, consumers are asked about the possible reduction they would like to perform for saving electricity and changes in load patterns are observed. Saving in electricity is observed for all the cases. Fig. 3 shows the block diagram of the methodology used.

Fig. 4 (a), Fig. 4(b) and Fig. 4(c) show daily average load curve for residential electricity users, daily average load pattern of lighting load and daily average load pattern of fan respectively. The peak demand occurs during 9:00 pm - 9:30 $\mathrm{pm}$ and the average peak is $1250.5 \mathrm{~W}$. Consumers use different appliances at different times. Use of lighting load is relatively high during 5:00 pm to 12:00 am and use of fan is relatively high during 6:30 pm- 8:00 am.

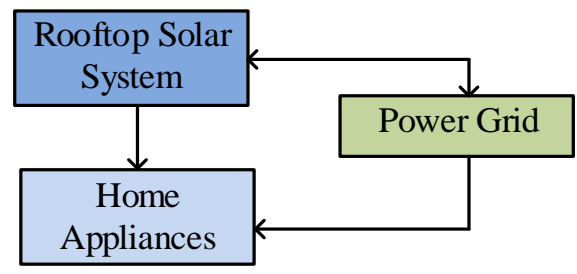

Fig. 2. Basic solar system for home 


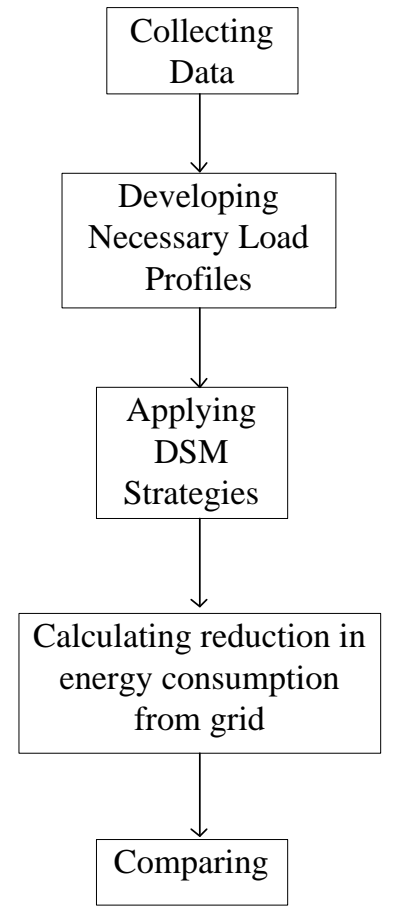

Fig. 3. Methodology



(a)

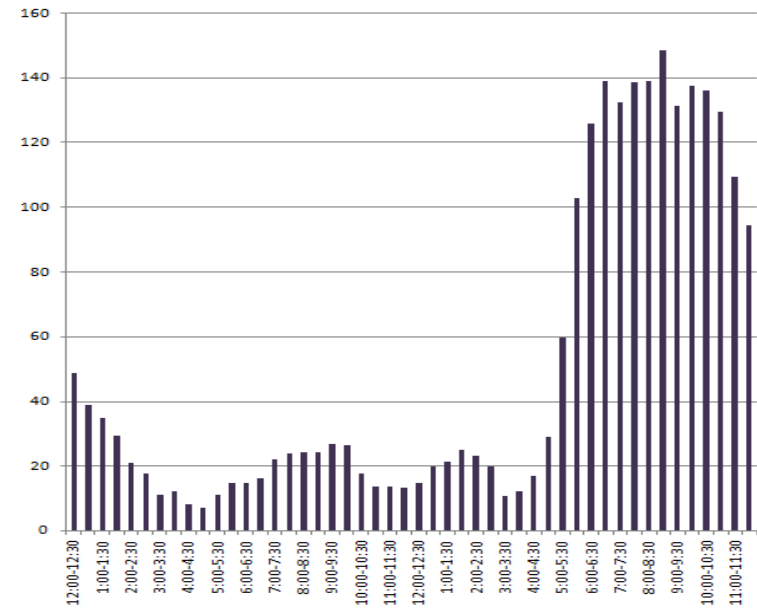

(b)

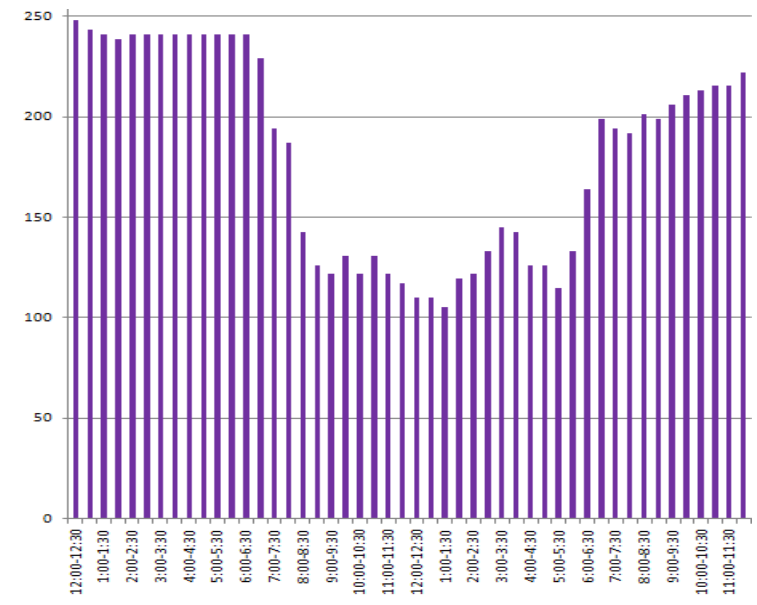

(c)

Fig. 4. (a) Daily average load curve for residential users, (b) Daily average load pattern of lighting load (c) Daily average load pattern of fan

\section{RESULTS AND ANALYSIS}

\section{A. Impact of Using Solar System}

Lighting load and fan can be used easily using solar energy for some periods of the day. It is considered that the solar system has energy storage capacity and is capable of supplying the power at desired time. Solar energy is used during 5:00 pm - 12:00 am for lighting load and during 6:30 pm - 8:00 am for fan. Fig. 5 indicates the solar power supplied to the lighting load and fan.

\section{B. Impact of Load Limiting}

According to this method, limit for $20 \%$ load limiting is been set during peak period ( $5 \mathrm{pm}-11 \mathrm{pm})$ and the value is $1000.40 \mathrm{~W}$. So, the highest demand during peak period is now 1000.4W. Fig. 6 shows the daily average load curve after applying load limiting method. 




(a)

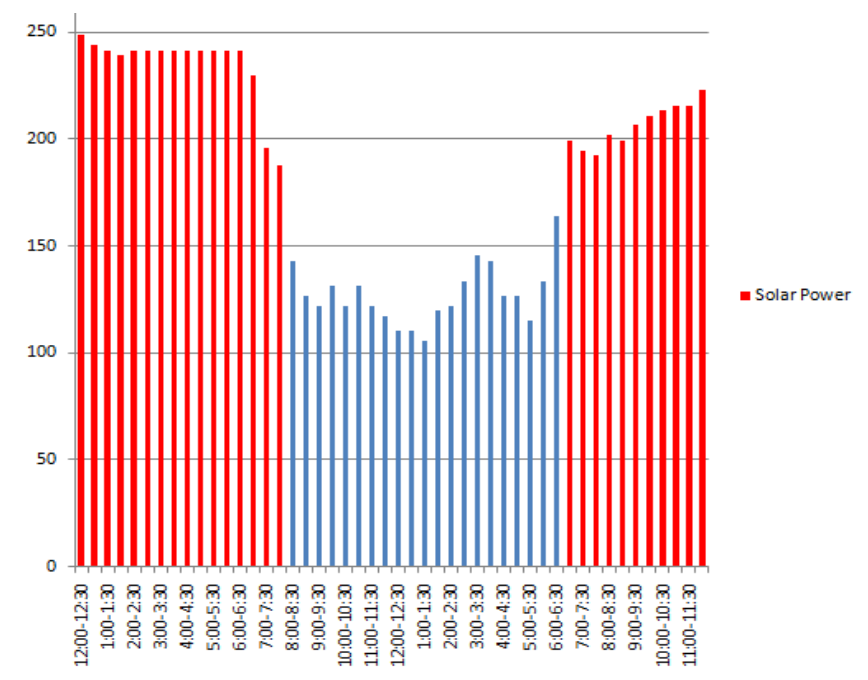

(b)

Fig. 5. Daily average load pattern of (a) lighting load and (b) fan after using solar system

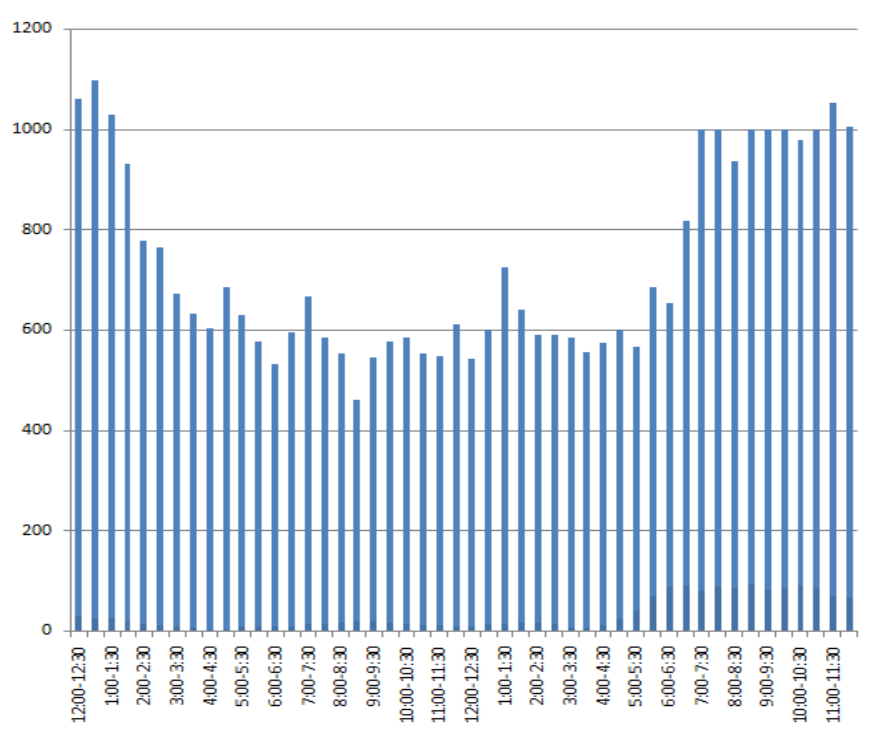

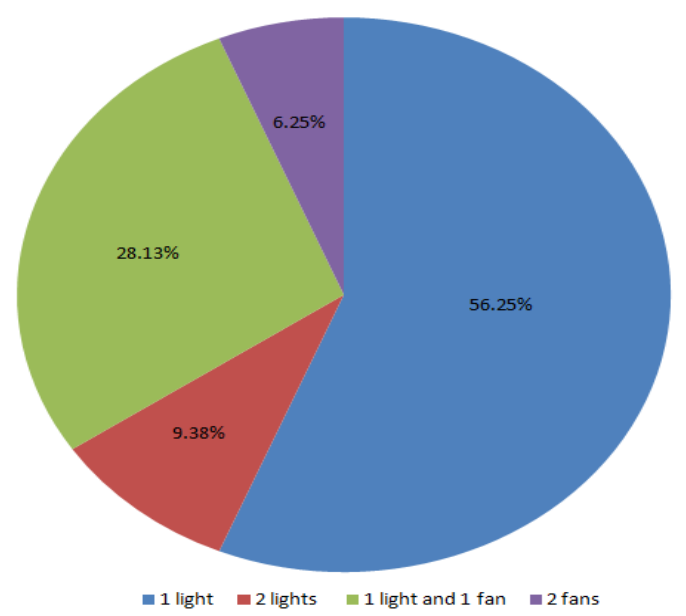

Fig. 7. Consumer's choice for saving electricity

\section{Impact of Deliberate Load Reduction}

In the case of load reduction, consumers are given the flexibility of reduction. They are asked about what they would like to do to reduce electrical energy consumption in peak period. Save in electricity is calculated on the basis of their opinion. From the collected data, it is found that, 56.25 $\%$ consumers are interested to turn a light OFF during peak period that they usually keep ON that time. $28.13 \%, 9.38 \%$ and $6.25 \%$ consumers are interested to turn OFF 1 light and 1 fan, 2 lights, 2 fans respectively. On an average, number of lighting load per household that can be turned OFF is 1.03 and average number of fan that can be turned OFF is 0.41 . Fig. 7 indicates the consumer's choice for saving electricity.

D. Unit saved

Average demand per day $=745.7 \mathrm{~W}$

Total units consumed per day $=745.7 \mathrm{~W}$ X $24 \mathrm{~h}$

$$
\begin{aligned}
& =17896.8 \mathrm{Wh} \\
& =17.8968 \text { units }
\end{aligned}
$$

Unit saving calculation for using solar system:

Unit saved for lighting load $=0.5 \times(59.6+103.1+125.8+$ $139.1+132.7+138.8+139.1+148.8+131.5+137.7+$ $136.2+129.5+138.6+94.3)$

$=877.2 \mathrm{Wh}$

$=0.8772$ unit

Unit saved for fan $=0.5 \times(199.2+194.5+192.1+201.6+$ $199.2+206.2+210.9+213.3+215.6+215.6+222.6+$ $284.4+243.8+241+239.1+241.4+241.3+241.3+241.3$ $+241.3+241.3+241.3+241.3+241.3+229.7+194.5+$ 187.5)

$=3031.5 \mathrm{Wh}$

$=3.0315$ units

Total units saved $=0.8772+3.0315$

$$
=3.9087 \text { units/day }
$$

So, $21.8 \%$ of daily average energy consumption from grid can be reduced.

Unit saving calculation for load limiting:

Fig. 6. Daily average load curve after applying load limiting method 
Total units saved $=0.5 \mathrm{x}[(1094.2-1000.4)+(1060.4-$ $1000.4)+(1108.8-1000.4)+(1250.5-1000.4)+(1218.1-$ $1000.4)+(113.6-1000.4)]$

$=441.6 \mathrm{Wh}$

$=0.4416$ unit $/$ day

For load limiting method, $2.46 \%$ of daily average energy consumption can be reduced.

Unit saving calculation for load reduction:

It has been considered that lighting load consumes $40 \mathrm{~W}$ and fan consumes $75 \mathrm{~W}$. So, 1.03 lights consume $(1.03 \times 40)=$ $41.2 \mathrm{~W}$ and 0.41 fan consumes $(0.41 \times 75)=30.8 \mathrm{~W}$.

Unit saved for lighting load $=0.5 \times[(59.6-41.2)+(103.1-$ $41.2)+(125.8-41.2)+(139.1-41.2)+(132.7-41.2)+$ $(138.8-41.2)+(139.1-41.2)+(148.8-41.2)+(131.5-$ $41.2)+(137.7-41.2)+(136.2-41.2)+(129.5-41.2)$ $=513.8 \mathrm{Wh}$

$=0.5138$ unit

Unit save for fan $=0.5 \times[(114.8-30.8)+(133.6-30.8)+$ $(164.1-30.8)+(199.2-30.8)+(194.5-30.8)+(192.1-$ $30.8)+(201.6-30.8)+(199.2-30.8)+(206.2-30.8)+$ $(210.9-30.8)+(213.3-30.8)+(215.6-30.8)$

$=937.8 \mathrm{Wh}$

$=0.9378$ unit

Total units saved $=0.5138+0.9378$

$$
=1.4516 \text { units } / \text { day }
$$

In this case, $8.11 \%$ of daily average energy consumption can be reduced.

E. Comparison

TABLE I. COMPARISON BETWEEN DIFFERENT DSM TOOLS

\begin{tabular}{|c|c|c|}
\hline $\begin{array}{c}\text { Demand Side Management } \\
\text { Tool }\end{array}$ & $\begin{array}{c}\text { Unit Saved per } \\
\text { day } \\
(\mathbf{K W h})\end{array}$ & $\begin{array}{c}\text { Percentage of } \\
\text { daily } \\
\text { consumption } \\
(\boldsymbol{\%})\end{array}$ \\
\hline Using Solar System & 3.9087 & 21.8 \\
\hline Load Limiting & 0.4416 & 2.46 \\
\hline Deliberate Load Reduction & 0.5138 & 8.11 \\
\hline Energy Efficiency & 3.5368 & 19.76 \\
\hline Direct Load Control & 0.3434 & 1.92 \\
\hline
\end{tabular}

Table I shows comparison between the three methods discussed in this paper and two traditional methods of [2]. It is clear that using solar system technique shows the best result. Energy efficiency also shows good result. Load limiting and road reduction can lead to better result than direct load control.

\section{CONCLUSIONS}

Among the three discussed DSM tools: using solar system, load limiting and deliberate load reduction, using solar system shows better result in terms of energy saving. Noticeable amount of energy consumption from grid can be reduced by using solar system. So, this method should be given priority to reduce energy consumption from grid. Using solar system, $21.8 \%$ of average daily energy consumption from grid can be reduced which results in reduction of emission of carbon dioxide by $2.32 \mathrm{~kg}$ per day. For load limiting method, $2.46 \%$ of average daily consumption can be reduced which results in reduction of emission of carbon dioxide by $0.26 \mathrm{~kg}$. In the case of deliberate load reduction, $8.11 \%$ of average daily energy consumption can be reduced which can reduce carbon dioxide emission by $0.86 \mathrm{~kg}$ without any cost. Furthermore, applying DSM strategies all together has enormous potential of saving electrical energy consumption.

\section{ACKNOWLEDGEMENT}

We are thankful to the department of EEE, Ahsanullah University of Science and Technology for providing the necessary support to complete this research.

\section{REFERENCES}

[1] P. Palensky, D. Dietrich, "Demand Side Management: Demand Response, Intelligent Energy Systems, and Smart Loads", IEEE Transactions on Industrial Informatics, vol. 7, no. 3, pp. 381-388, Aug 2011

[2] G. Gaur, N. Mehta, R. Khanna, S. Kaur, "2017 Demand Side Management in a Smart Grid Environment" IEEE International Conference on Smart Grid and Smart Cities (ICSGSC), Singapore, July 2017.

[3] K. Wang, H. Li, S. Maharjan, Y. Zhang, S. Guo, "Green Energy Scheduling for Demand Side Management in the Smart Grid",vol. 2, no. 2, pp. 596-611, June 2018.

[4] Zone Wise Supply against Highest Generation, Available at: https://pgcb.org.bd/PGCB/?a=pages/maxgen_display.php (last accessed on June 3, 2019).

[5] Ayman Uddin Mahin, Md. Adnan Sakib, Md. Asif Zaman, Md. Shahed Chowdhury, Saik Ahsan Shanto, "Developing Demand Side Management Program for Residential Electricity Consumers of Dhaka City", International Conference on Electrical, Computer and Communication Engineering (ECCE), Cox's Bazar, Feb 16-18, 2017.

[6] F. Boshell and O. P. Veloza, "Review of developed demand side management programs including different concepts and their results," IEEE/PES Transmission and Distribution Conference and Exposition: Latin America, Bogota, Aug 13-15, 2008.

[7] R. Alaileh, M. Yousif, A. Fadul and M. Preece, "Energy efficiency and demand side management in Abu Dhabi," 2013 7th IEEE GCC Conference and Exhibition (GCC), Doha, Nov 17-20, 2013.

[8] B. K. Nallamothu, C. Selvam, K. Srinivas and S. Prabhakaran, "Study on energy savings by using efficient utilites in buildings," 2015 Communication, Control and Intelligent Systems (CCIS), Mathura, Nov 7-8, 2015

[9] R. Sharma and R. K. Jain, "Energy audit of residential buildings to gain energy efficiency credits for LEED certification," 2015 International Conference on Energy Systems and Applications, Pune, Oct 30-Nov 1, 2015

[10] A. Salami and M. M. Farsi, "Demand side management using direct load control for residential and industrial areas," 2015 International Congress on Electric Industry Automation (ICEIA 2015), Shiraz, Feb 24-15, 2015.

[11] M. S. Majid, H. A. Rahman, M. Y. Hassan and C. A. Ooi, "Demand Side Management Using Direct Load Control for Residential," 2006 4th Student Conference on Research and Development, Selangor, June 27-28, 2006.

[12] H. Mortaji, S. H. Ow, M. Moghavvemi and H. A. F. Almurib, "Load Shedding and Smart-Direct Load Control Using Internet of Things in Smart Grid Demand Response Management," IEEE Transactions on Industry Applications, vol. 53, no. 6, pp. 5155-5163, 2017. 
[13] M. A. A. Pedrasa, M. M. Oro, N. C. R. Reyes and J. R. I. Pedrasa, "Demonstration of direct load control of air conditioners in high density residential buildings," 2014 IEEE Innovative Smart Grid Technologies - Asia (ISGT ASIA), Kuala Lumpur, May 20-23, 2014.

[14] L. Zhao, Z. Yang and W. Lee, "The Impact of Time-of-Use (TOU) Rate Structure on Consumption Patterns of the Residential Customers," in IEEE Transactions on Industry Applications, vol. 53, no. 6, pp. 5130-5138, 2017.

[15] A. S. Leger, E. Sobiesk, A. Farmer and B. Rulison, "Demand response with photovoltaic energy source and Time-of-Use pricing," 2014 IEEE PES T\&D Conference and Exposition, Chicago, IL, Apr 14-17, 2014.

[16] H. Ardeshiri, S. M. Barakati and K. Ranjbar, "Using improved time of use demand response in optimal operation of microgrid," 2015 20th Conference on Electrical Power Distribution Networks Conference (EPDC), Zahedan, Apr 28-19, 2015.

[17] Ravishankar A. N., Ashok S. and Kumaravel S., "Effects of demand side management \& storage on renewable energy penetration to the grid," 2017 Third International Conference on Advances in Electrical, Electronics, Information, Communication and Bio-Informatics (AEEICB), Chennai, Feb 27-28, 2017.

[18] A. Baldauf, "A smart home demand-side management system considering solar photovoltaic generation," 2015 5th International Youth Conference on Energy (IYCE), Pisa, May 27-30, 2015.

[19] G. G. Pillai, G. A. Putrus and N. M. Pearsall, "The potential of demand side management to facilitate PV penetration," 2013 IEEE Innovative Smart Grid Technologies-Asia (ISGT Asia), Bangalore, Nov 10-13, 2013.

[20] G. R. Hemanth, S. C. Raja, S. Suganya and P. Venkatesh, "Neural Network Based Demand Side Management Using Load Shifting," 2018 National Power Engineering Conference (NPEC), Madurai, Mar 9-10, 2018.

[21] N. Loganathan and K. Lakshmi, "Demand side energy management system using ANN based linear programming approach," 2014 IEEE International Conference on Computational Intelligence and Computing Research, Coimbatore, Dec 18-20, 2014.

[22] M. P. Raju and A. J. Laxmi, "A novel load management algorithm for EMU by implementing demand side management techniques using ANN," 2017 International Conference on Electrical and Computing Technologies and Applications (ICECTA), Ras Al Khaimah, Nov 2123, 2017. 